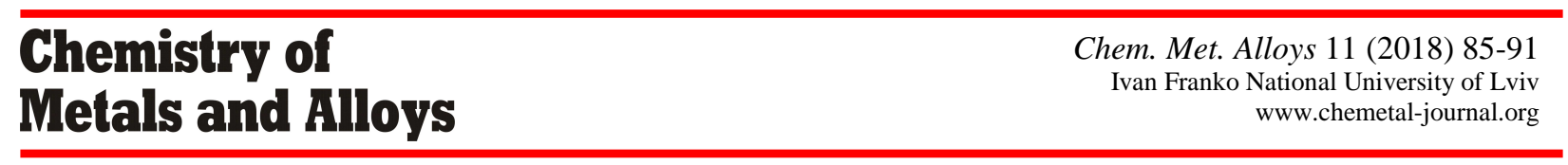

\title{
Dependence of hydrogen sorption-desorption on the structure of amorphous and amorphous-crystalline $\mathrm{Fe}_{62.7} \mathrm{Nd}_{33.7} \mathrm{~B}_{1.1} \mathrm{Cu}_{1.5} \mathrm{Ti}_{1.0}$ alloys
}

\author{
Gregory BREKHARYA ${ }^{1}$, Tetyana PRYADKO ${ }^{2}$, Volodymyr DEKHTYARENKO ${ }^{2 *}$, Vasyl LYAKISHEV ${ }^{1}$, \\ Nataliya LYASHENKO ${ }^{3}$, Vira BOVDA ${ }^{4}$ \\ ${ }^{1}$ Department of Crystallization, G.V. Kurdyumov Institute for Metal Physics of NASU, \\ Akad. Vernadsky Ave. 36, 03142 Kyiv, Ukraine \\ ${ }^{2}$ Laboratory of Eutectic Alloys, G.V. Kurdyumov Institute for Metal Physics of NASU, \\ Akad. Vernadsky Ave. 36, 03142 Kyiv, Ukraine \\ ${ }^{3}$ Department of Condensed Matter Physics, Metallurgical Faculty, Dniprovsk State Technical University, \\ Dniprobudivska St. 2, 51918 Kamyanske, Dnipropetrovsk region, Ukraine \\ ${ }^{4}$ Institute of Solid State Physics, Materials Science and Technologies of NASU, National Science Center \\ "Kharkiv Institute of Physics and Technology”, Akademichna St. 1, 61108 Kharkiv, Ukraine \\ * Corresponding author.Tel.+380-44-4241220; e-mail: devova@i.ua
}

Received June 23, 2018; accepted December 26, 2018; available on-line March 29, 2019

Thin films of $\mathrm{Fe}_{62.7} \mathrm{Nd}_{33.7} \mathrm{~B}_{1.1} \mathrm{Cu}_{1.5} \mathrm{Ti}_{1.0}$ alloy, promising for use as permanent magnets with high values of $H_{\mathrm{Cj}}$ and $B_{\mathrm{r}}$, were obtained by quenching from the liquid state in pure helium atmosphere. The sorption properties and kinetics parameters of the hydrogenation and dehydrogenation processes of amorphous and amorphouscrystalline alloys were investigated by Sieverts' method. The temperature of onset of intensive hydrogen absorption was determined by the kinetic dependence $T=f(\tau), p=f(\tau)$. The amount of absorbed hydrogen $m_{H}[\mathrm{~g}]$ and the hydrogenation rate change $v[\mathrm{~g} / \mathrm{s}]$ in the process of hydrogen saturation were calculated from the pressure change in a closed volume. It was established that the hydrogenation process is controlled by the degree of amorphousness of the obtained thin films. The more amorphous the component, the slower the hydrogen absorption, and it occurs at higher temperatures. It was found that at $\sim 790 \pm 5 \mathrm{~K}$ the amorphous component decomposes into an equilibrium of $\mathrm{Nd}, \mathrm{Fe}_{14} \mathrm{Nd}_{2} \mathrm{~B}$, and $\mathrm{Fe}_{4} \mathrm{Nd}_{1,1} \mathrm{~B}_{4}$ phases in both types of film and precipitated Nd takes part in the hydrogenation process at this temperature. The coexistence of two metal hydride phases possessing different properties is possible in partially hydrogenated films and their volume ratio can be regulated by appropriate selection of the sorption-desorption process parameters. The hydrogen brittleness of the samples may be used to obtain microstructured films with a grain size of 50-300 $\mathbf{~ n m}$.

Permanent magnets / Amorphous-crystalline state / Hydrogenation-dehydrogenation process / Disproportionation / Hydride phases

\section{Introduction}

Until recently, despite intensive use of HDDR methods for the production and recycling of $\mathrm{Nd}-\mathrm{Fe}-\mathrm{B}$ magnets, relatively few studies have been performed on HDDR of amorphous and amorphous-crystalline $\mathrm{Nd}-\mathrm{Fe}-\mathrm{B}$ alloys. Previous studies have indicated that the temperature and rate of hydrogen absorption and desorption strongly depend on the initial state and composition of the material [1-3]. The quenching rate (wheel speed) of melt-spun $\mathrm{Nd}-\mathrm{Fe}-\mathrm{B}$ ribbons with moderate amounts of Nd-rich phase produces a decrease of the hydrogen disproportionation temperature to $530^{\circ} \mathrm{C}$. Moreover, the amount of amorphous-like component strongly influences the hydrogen absorption behavior, resulting in an increase of the initial hydrogen absorption temperatures up to $200-300^{\circ} \mathrm{C}$ and leading to a two-step disproportionation. The raise of the initial absorption temperature of the melt-spun ribbons was attributed to improved chemical stability and better inertness compared to large-grain alloys [1], but the low disproportionation temperature of amorphous-like alloys was connected with more rapid hydrogen diffusion in such materials [2].

It is well known that melt-spinning conditions influence the microstructure through the thickness of the flakes, resulting in phase and morphological 
variations [3-5]. It was found that small additions of $\mathrm{Ti}$ and $\mathrm{Cu}$ modified the crystallization behavior of melt-spun alloys by suppressing nucleation of the $\alpha$-Fe phase, which resulted in enhanced magnetic properties [6].

Improvement of the particle uniformity can be reached by the crushing method in hydrogen environment. The effect of hydrogen brittleness consists in the possibility to destroy materials and obtain stress-free powders for further use in manufacturing techniques of high-quality alloys by powder metallurgy methods. Here, as a rule, it is supposed that the absorbed hydrogen can be removed later during annealing in vacuum at relatively low temperatures. Besides, positive influence of hydrogenation on the magnetic properties of $R_{2} \mathrm{Fe}_{14} \mathrm{~B}$ compounds has been revealed [7]. According to Sugimoto and Book [8] the interaction of $\mathrm{Fe}_{14} \mathrm{Nd}_{2} \mathrm{~B}$ with hydrogen can be presented as follows:

$$
\mathrm{Fe}_{14} \mathrm{Nd}_{2} \mathrm{~B}+(2 \pm x) \mathrm{H}_{2} \leftrightarrows
$$$$
12 \alpha-\mathrm{Fe}+2 \mathrm{NdH}_{2 \pm x}+\mathrm{Fe}_{2} \mathrm{~B} \pm \Delta H
$$

However, the kinetics of the process of hydrogenation of amorphous and amorphouscrystalline alloys of the system $\mathrm{Fe}-\mathrm{Nd}-\mathrm{B}$ have not been sufficiently studied. Therefore, the aim of the present work was to obtain films of $\mathrm{Fe}-\mathrm{Nd}-\mathrm{B}$ alloy doped with $\mathrm{Cu}$ and $\mathrm{Ti}$ by quenching from the liquid state, to determine regularities of their structural changes and conditions of disproportionation under the influence of hydrogen. We also decided to study the possibility to obtain powders of a given grain size due to the hydrogen brittleness of the samples.

\section{Materials and methods}

The composition used in the investigation was $\mathrm{Nd}_{15.5} \mathrm{Fe}_{74.7} \mathrm{~B}_{6.8} \mathrm{Cu}_{1.6} \mathrm{Ti}_{1.4}$. The initial alloy was vacuum-melted from high-purity components (Nd 99.8\%; Fe 99.0\%; ferroboron $\mathrm{Fe}_{80} \mathrm{~B}_{20}$ (wt.\%); $\mathrm{Cu}$ 99.6\%; Ti 98.6\%). $\mathrm{Nd}_{15.5} \mathrm{Fe}_{74.7} \mathrm{~B}_{6.8} \mathrm{Cu}_{1.6} \mathrm{Ti}_{1.4}$ ribbons were obtained by melt-spinning in helium atmosphere. The wheel speed was $20 \mathrm{~m} / \mathrm{s}$. The thickness of the melt-spun ribbons, estimated by optical microscopy, was in the range of $10-50 \mu \mathrm{m}$. Hydrogen absorption/desorption studies were carried out using a
Sievert type apparatus at a heating rate of $4^{\circ} \mathrm{C} / \mathrm{min}$ [9]. The melt-spun ribbons were placed into the working reactor, which was pumped out to a vacuum of down to $1.33 \cdot 10^{-6} \mathrm{MPa}$. Then, the melt-spun ribbons were heated in hydrogen atmosphere at a pressure of $0.5 \mathrm{MPa}$, from room temperature to $670^{\circ} \mathrm{C}$.

The amount of absorbed hydrogen was determined by weighing the samples with an accuracy of $1.5 \cdot 10^{-5} \mathrm{~g}$ and calculated from the pressure change in a closed volume. The hydrogen desorption was studied after pumping out the working reactor to $\sim 2 \cdot 10^{-4} \mathrm{MPa}$ in heating mode and at $T \approx 500^{\circ} \mathrm{C}$ for isothermal processing.

The microstructure was investigated by scanning electronic microscopy (REM-106I) and optical microscopy (NEOPHOT-32). Metallographic samples were prepared by the standard technique with final polishing. Phase composition and crystal lattice parameters were determined by X-ray diffraction using a DRON-3M diffractometer with a standard goniometer GUR-8 and $\mathrm{Cu}-K_{\alpha}$ monochromatic radiation. The size of the crystals after hydrogenation was calculated by the Shayl-Schwarz-Saltykov method [10].

\section{Results and discussion}

According to the $\mathrm{X}$-ray diffraction spectra, the initial cast alloy consisted of three phases: $\mathrm{Fe}_{14} \mathrm{Nd}_{2} \mathrm{~B}$ $\left(P 4_{2} / m n m\right), \mathrm{Fe}_{4} \mathrm{Nd}_{1.1} \mathrm{~B}_{4}\left(P 4_{2} / n\right)$ and $\mathrm{Nd}\left(P 6_{3} / m m c\right)$, which is in agreement with the equilibrium $\mathrm{Nd}-\mathrm{Fe}-\mathrm{B}$ phase diagram [11]. In order to obtain a fine microstructure, the alloy was subjected to meltspinning. This way samples in the form of ribbons in "amorphous" and amorphous-crystalline state were obtained. It was observed that the elastic properties of the melt-spun ribbons heavily depended on their thickness. The microstructure of the melt-spun ribbons was also found to vary with the thickness (Fig. 1). Thin flakes $(\leq 10 \mu \mathrm{m})$ showed a homogeneous two-phase nanoscale structure (Fig. 1a), whereas medium thickness ribbons $(10 \leq \delta \leq 20 \mu \mathrm{m})$ contained somewhat dispersed inclusions in the |matrix (Fig. 1b). The latter can be attributed to the amorphous state with frozen-in crystals.
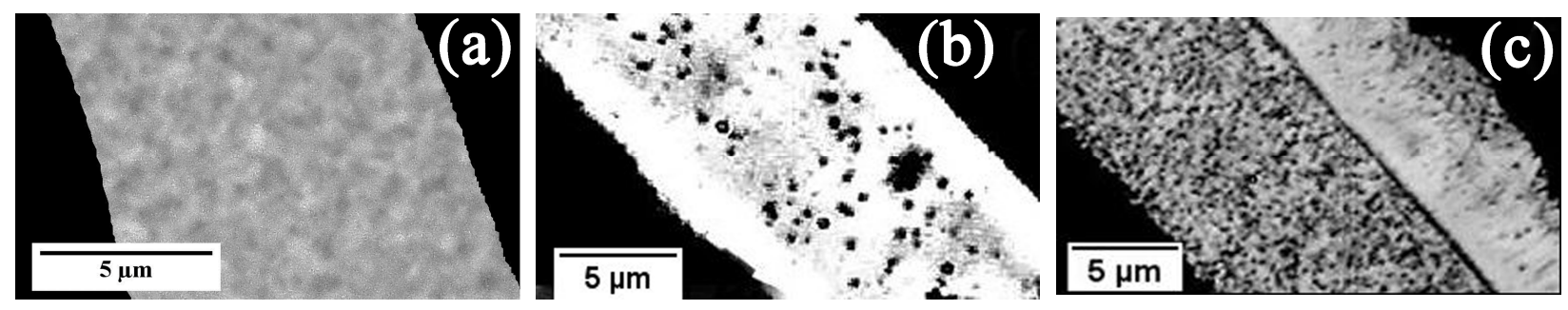

Fig. 1 Microstructure of cross-sections of films of rapidly quenched alloys $\mathrm{Fe}_{62.7} \mathrm{Nd}_{33.7} \mathrm{~B}_{1.1} \mathrm{Cu}_{1.5} \mathrm{Ti}_{1.0}$ in amorphous" (a) and amorphous-crystalline (b, c) state. 
Thick flakes $(\geq 20 \mu \mathrm{m})$ revealed a slightly different pattern including both amorphous-crystalline and nearly crystalline regions (Fig. 1c). The crystalline component was calculated to about $40 \%$ for mid-sized $(10 \leq \delta \leq 20 \mu \mathrm{m})$ and $70 \%$ for thick flakes $(\geq 20 \mu \mathrm{m})$ (Fig. 1b,c), respectively. These results are in agreement with the X-ray diffraction analysis of the melt-spun ribbons (Fig. 2). The spectra revealed the presence of an amorphous halo and diffraction peaks of the $\mathrm{Nd}_{2} \mathrm{Fe}_{14} \mathrm{~B}$ and $\mathrm{Nd}_{1.1} \mathrm{Fe}_{4} \mathrm{~B}_{4}$ phases. A small amount of $\mathrm{NdCu}_{2}$ phase (Imma) was also observed. This points to non-equilibrium crystallization of the multi-component $\mathrm{Nd}_{15.5} \mathrm{Fe}_{74.7} \mathrm{~B}_{6.8} \mathrm{Cu}_{1.6} \mathrm{Ti}_{1.4}$ alloy and formation of $\mathrm{NdCu}_{2}$ phase of limited stability $[12,13]$. Additionally, it was found that thin melt-spun ribbons (Fig. 1a) possess good elastic properties, but the flakes in the amorphous state with frozen-in crystals (Fig. 1b), as well as those in the amorphous-crystalline state (Fig. 1c), are more brittle.

Mid-sized melt-spun ribbons $(10 \leq \delta \leq 20 \mu \mathrm{m})$ in the amorphous state with frozen-in crystals, and thick flakes $(\geq 20 \mu \mathrm{m})$ (Fig. 1b,c) in the amorphouscrystalline state, were chosen for the hydrogenation. However, it should be noted that precise separation could not be guaranteed due to some technological aspects. Hydrogenation was carried out at an initial hydrogen pressure of $\sim 0.5 \mathrm{MPa}$ in heating regime in the temperature range from room temperature to $920 \mathrm{~K}$ (Fig. 3,I,III), as well as under isobaricisothermal conditions at temperatures of 780-790 K (Fig. 3,II) and 910-920 K (Fig. 3,IV).

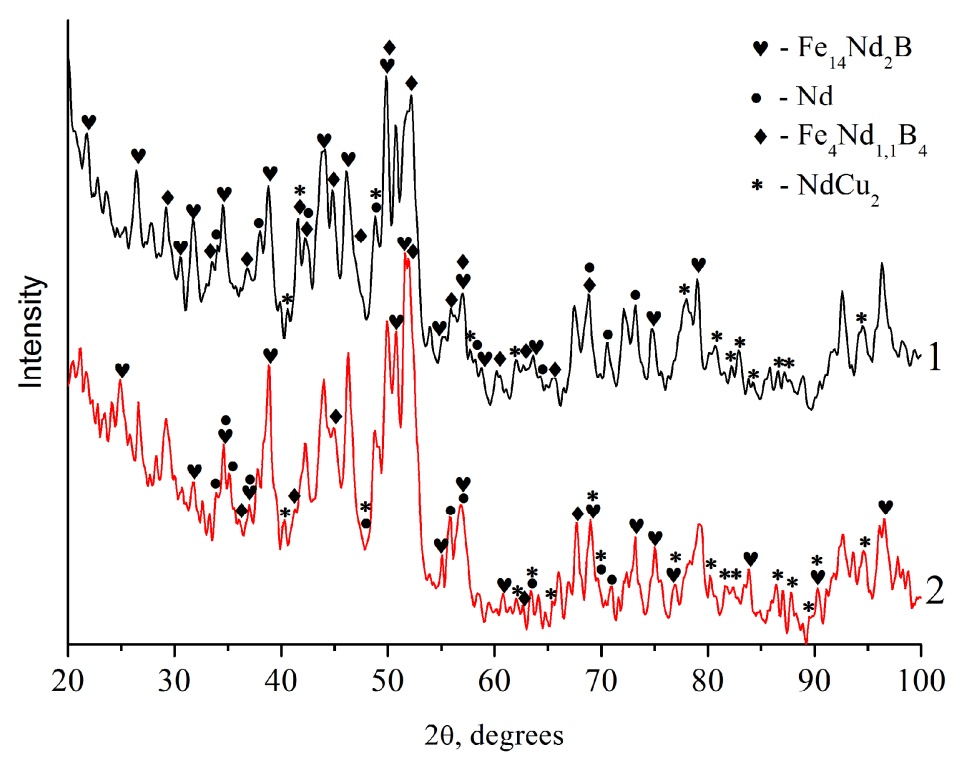

Fig. $2 \mathrm{X}$-ray diffraction pattern of the films obtained by quenching the $\mathrm{Fe}_{62.7} \mathrm{Nd}_{33.7} \mathrm{~B}_{1.1} \mathrm{Cu}_{1.5} \mathrm{Ti}_{1.0}$ alloy from the liquid state: 1 - contact surface, 2 - free surface.

(a)
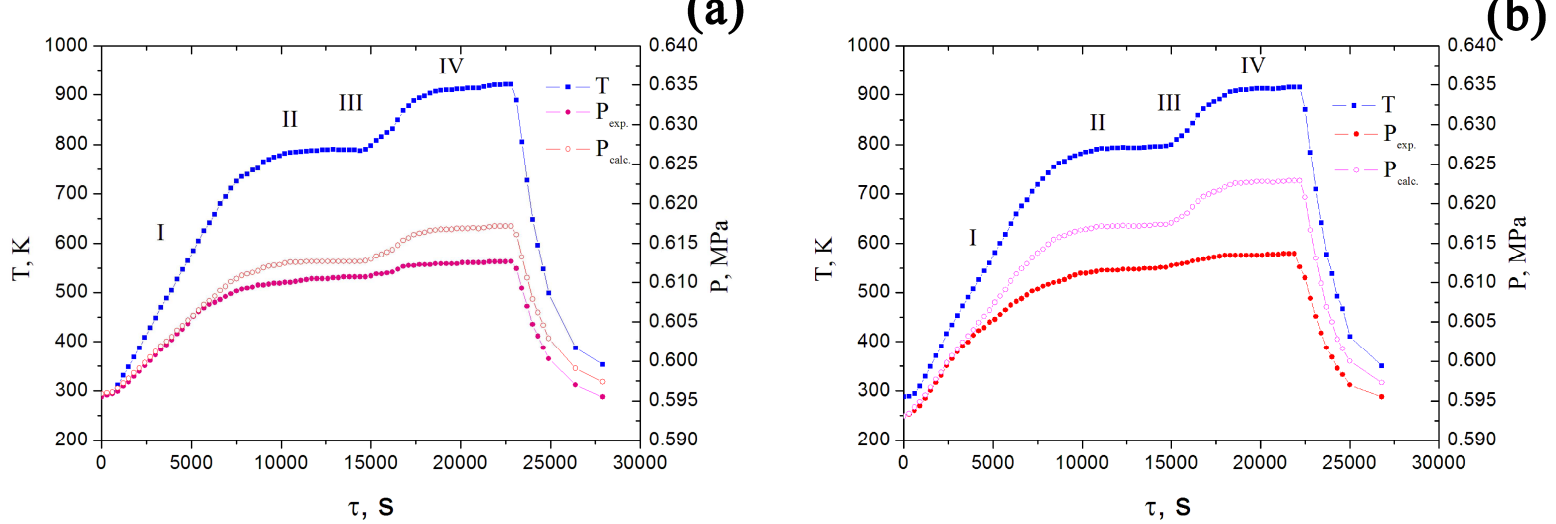

Fig. 3 Change of pressure and temperature in the reactor during hydrogenation of $\mathrm{Fe}_{62.7} \mathrm{Nd}_{33.7} \mathrm{~B}_{1.1} \mathrm{Cu}_{1.5} \mathrm{Ti}_{1.0}$ alloy films in "amorphous" (a) and amorphous-crystalline (b) state. 
The hydrogen absorption was determined from the kinetic dependencies of $T=\mathrm{f}(\tau)$ and $p=\mathrm{f}(\tau)$ (Fig. 3). The amount of absorbed hydrogen, $m_{\mathrm{H}}[\mathrm{g}]$ (Fig. 4), and the hydrogenation rate, $v[\mathrm{~g} / \mathrm{s}]$ (Fig. 5), were calculated from the pressure change in a closed volume.

As can be seen in Fig. 4, intensive absorption of hydrogen in the amorphous-crystalline ribbons started at a lower temperature than for the amorphous ribbons ( $\sim 90$ and $585 \mathrm{~K}$, respectively), which is consistent with results obtained in previous studies [1,2]. Then the hydrogen absorption slowed down in the temperature range of $780-790 \mathrm{~K}$ for both types of ribbon (25 min for the amorphous-crystalline and 40 min for the "amorphous" state). Further holding for one hour at 780-790 K did not lead to any increase of the amount of absorbed hydrogen, yielding a maximum hydrogen capacity $C_{\mathrm{H}}$ of about $0.55 \mathrm{wt} \%$ per $1 \mathrm{~g}$ of $\mathrm{Nd}$ metal. A rise in temperature relaunched the hydrogenation leading to a second peak of fast hydrogen intake at $\sim 790 \pm 5 \mathrm{~K}$. Such behavior was observed both for the "amorphous" and amorphous-crystalline samples and corresponds to the decomposition of the amorphous component to the equilibrium $\mathrm{Nd}, \mathrm{Nd}_{2} \mathrm{Fe}_{14} \mathrm{~B}$, and $\mathrm{Nd}_{1.1} \mathrm{Fe}_{4} \mathrm{~B}_{4}$ phases and rapid interaction of precipitated $\mathrm{Nd}$ with hydrogen.

The kinetics of the hydrogen absorption in the melt-spun ribbons can be described by the change of the hydrogenation rate $v$ [g/s] (Fig. 5). It can be seen that the process consists of several transformations. Each transformation depends on the initial state of the sample and possesses its own kinetic parameters. Fig. 5 shows that the hydrogen absorption at the first stage (I) corresponds to the formation of a $\mathrm{Nd}_{2} \mathrm{Fe}_{14} \mathrm{BH}_{x}$-type hydride and hydriding of the Nd-rich and amorphous phases. The amount of hydrogen absorbed at this stage and the presence of $\mathrm{Nd}_{2} \mathrm{H}_{5}$ hydride (see Fig. 6) suggest that the "amorphous" and amorphous-crystalline alloys contained $13.65 \%$ and $11.31 \%$ of free $\mathrm{Nd}$, respectively (dark inclusions in Fig. 1b,c).

(a)

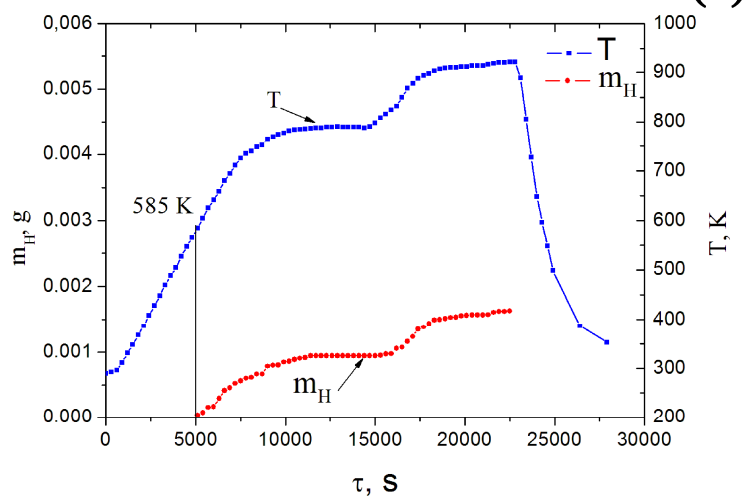

(b)

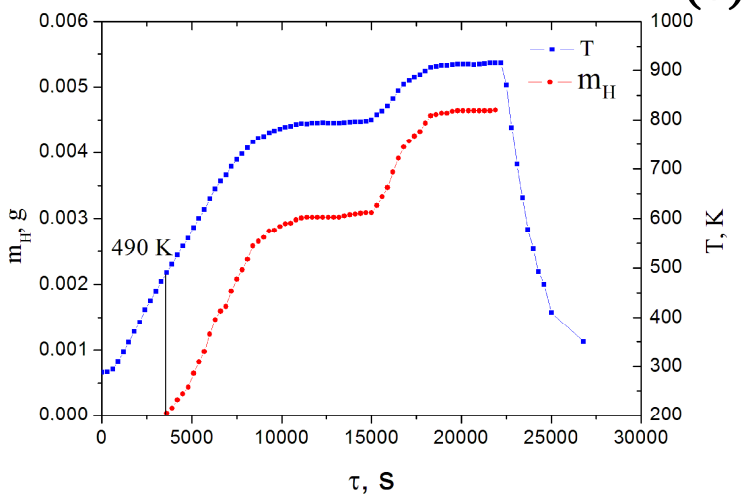

Fig. 4 Amount of hydrogen absorbed by $\mathrm{Fe}_{62.7} \mathrm{Nd}_{33.7} \mathrm{~B}_{1.1} \mathrm{Cu}_{1.5} \mathrm{Ti}_{1.0}$ alloy films in "amorphous" (a) and amorphous-crystalline (b) state during the process of hydrogenation.

(a)
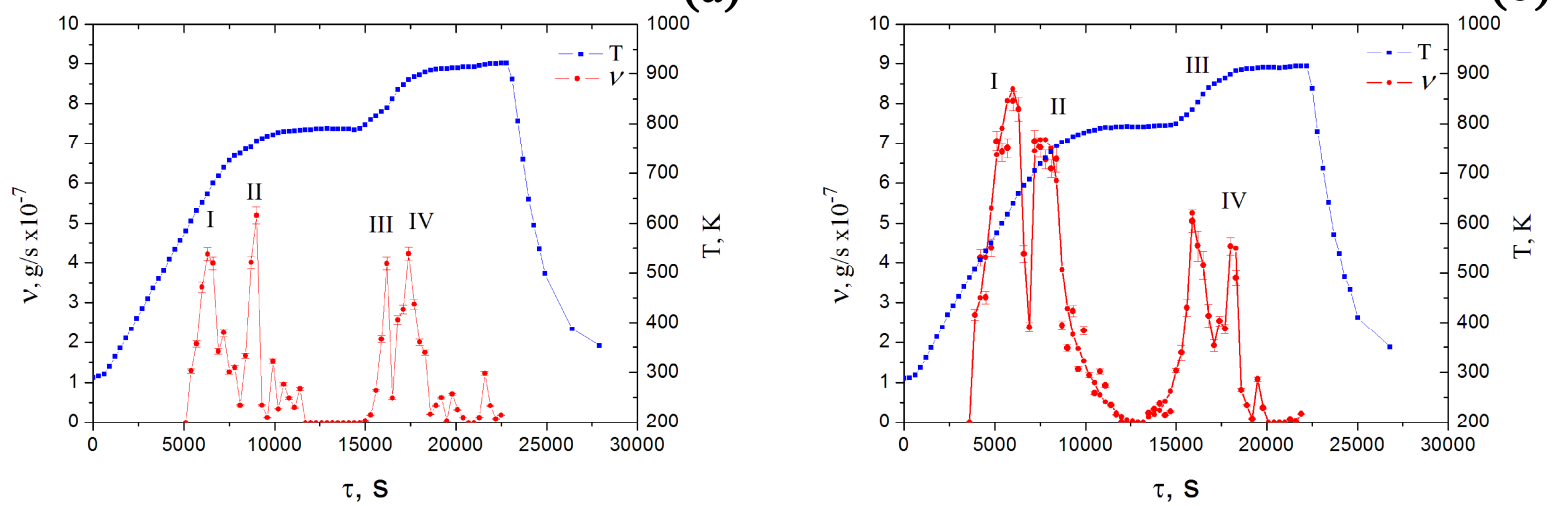

Fig. 5 Rate of the hydrogenation of $\mathrm{Fe}_{62.7} \mathrm{Nd}_{33.7} \mathrm{~B}_{1.1} \mathrm{Cu}_{1.5} \mathrm{Ti}_{1.0}$ alloy films in "amorphous" (a) and amorphouscrystalline (b) state during the process of hydrogen saturation. 


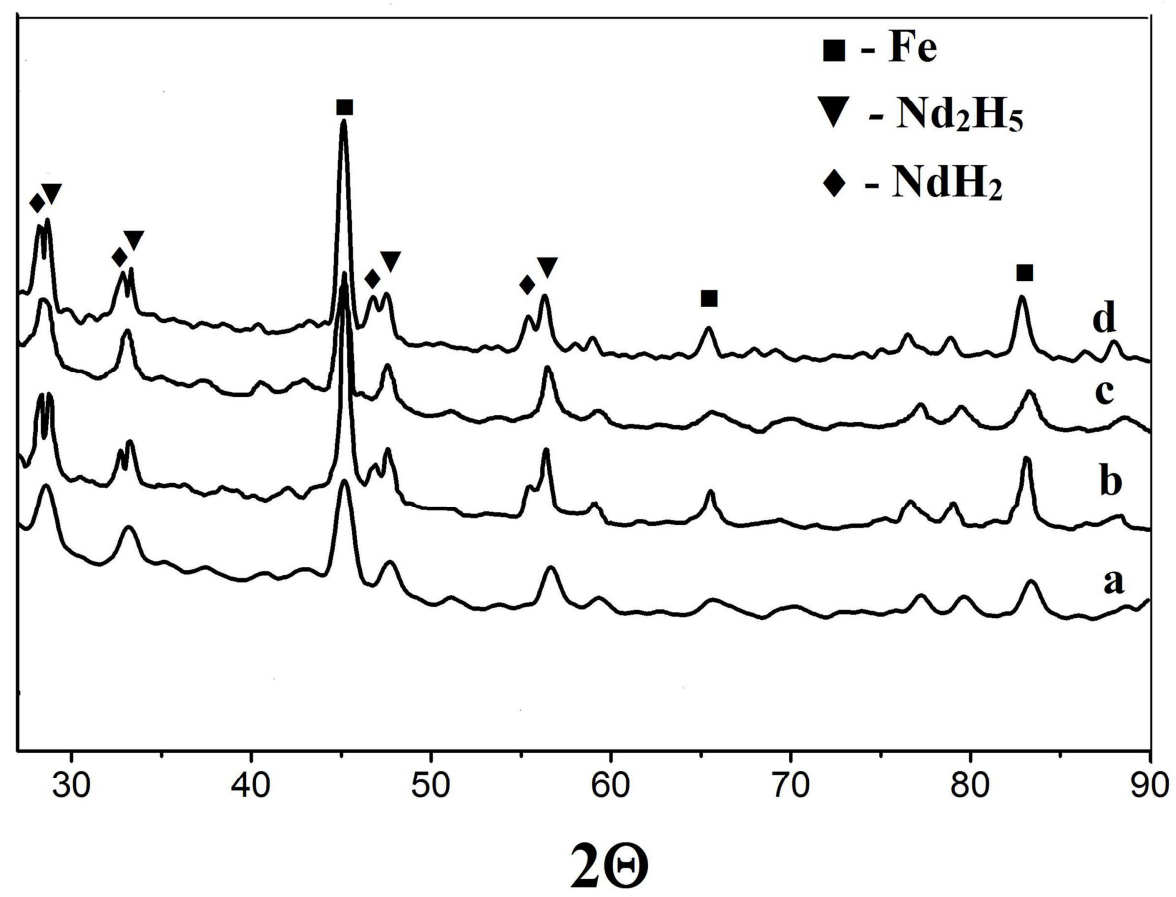

Fig. 6 X-ray diffraction patterns of hydrogenated (a, c) and dehydrogenated (b, d) $\mathrm{Fe}_{62.7} \mathrm{Nd}_{33.7} \mathrm{~B}_{1.1} \mathrm{Cu}_{1.5} \mathrm{Ti}_{1.0}$ alloy films $\left(\mathrm{a}, \mathrm{b}-1^{\text {st }}\right.$ cycle, $\mathrm{c}, \mathrm{d}-2^{\text {nd }}$ cycle).

Further rise of the temperature (stage II) led to decomposition of the amorphous phase and formation of a $\mathrm{Nd}_{2} \mathrm{Fe}_{14} \mathrm{BH}_{x}$ phase and stoichiometric $\mathrm{Nd}_{2} \mathrm{H}_{5}$ hydride. Calculations showed that the disproportionation of the amorphous phase resulted in an increase of free $\mathrm{Nd}$ to $27.25 \%$ in the "amorphous" sample, and up to $34.28 \%$ in the amorphouscrystalline sample. Moreover, it can be seen from Figs. 4 and 5 that intensive hydrogen intake in the amorphous-crystalline sample started at lower temperatures (stage I $490 \mathrm{~K}$ and stage II $700 \mathrm{~K}$ ) than in the "amorphous" sample (stage I $585 \mathrm{~K}$ and stage II $740 \mathrm{~K}$ ). This may suggest that the presence of an amorphous phase prevents the transport of hydrogen atoms deep into the sample, in particular to areas with frozen-in crystals.

At the last stages (III-IV) (Fig. 5), the decomposition of the $\mathrm{Nd}_{2} \mathrm{Fe}_{14} \mathrm{~B}$ phase is accompanied by the formation of $\mathrm{NdH}_{x}, \mathrm{Fe}_{2} \mathrm{~B}$, and $\alpha$-Fe. As illustrated by Fig. 5, intensive hydrogen absorption started in the same temperature range, $790-795 \mathrm{~K}$, for both samples and similar amounts of accumulated hydrogen per $1 \mathrm{~g} \mathrm{Nd}, 1.50-1.60 \mathrm{mg}$, were observed.

The absorption capacity of the melt-spun samples after cooling to room temperature in hydrogen was about $C_{\mathrm{H}} \approx 0.97$ wt. $\%$ per $1 \mathrm{~g}$ of $\mathrm{Nd}$ (formula ratio $\mathrm{H} / \mathrm{Me}=1.40$ ) for the "amorphous" and $C_{\mathrm{H}} \approx 0.84$ wt.\% per $1 \mathrm{~g}$ of $\mathrm{Nd}(\mathrm{H} / \mathrm{Me}=1.22)$ for the amorphous-crystalline sample. The concentration of absorbed hydrogen measured by the pressure drop in a closed volume coincided with the weight change of the hydrogenated samples. Small discrepancies between the experimental and calculated amounts of absorbed hydrogen can be explained by the presence of $\mathrm{Nd}_{1.1} \mathrm{Fe}_{4} \mathrm{~B}_{4}$ and $\mathrm{NdCu}_{2}$ in the initial samples. It is likely that these phases did not react with $\mathrm{H}_{2}$ under these conditions.

The formation of stoichiometric $\mathrm{Nd}_{2} \mathrm{H}_{5}$ hydride $\left(I 4{ }_{1} m d\right)$ under hydrogenation of melt-spun ribbons was confirmed by X-ray diffraction (Fig. 6a,c) for both the "amorphous" and amorphous-crystalline samples.

An important feature of the X-ray patterns of partially dehydrogenated melt-spun ribbons (Fig. 6b) was the presence of double diffraction peaks ("doubling") in the region of the $\mathrm{Nd}_{2} \mathrm{H}_{5}$ phase lines. This could be due to the presence of reflections from planes of the $f c c-\mathrm{NdH}_{2}$ phase $(F m-3 m)$. This effect disappeared after repeated hydrogenation. Splitting of the diffraction peaks of the $\mathrm{Nd}_{2} \mathrm{H}_{5}$ phase and appearance of reflections from the $\mathrm{NdH}_{2}$ phase were observed at the end of every absorption-desorption cycle (Fig. 6d). These results demonstrate that the coexistence of two metal hydride phases possessing different properties is possible in partially hydrogenated melt-spun ribbons. The phase ratio of the $\mathrm{Nd}_{2} \mathrm{H}_{5} / \mathrm{NdH}_{2}$ hydrides can be altered by the absorption-desorption parameters.

The applied processing mode $T \approx 820 \mathrm{~K}$, $p \approx 2 \cdot 10^{-4} \mathrm{MPa}$ allowed us to remove about $25 \%$ of the absorbed hydrogen. However, full recombination required higher temperatures for both the 
"amorphous" and the amorphous-crystalline samples. Cyclic absorption-desorption cycles reduced the hydrogen capacity $C_{\mathrm{H}}$ to $\sim 5-7 \%$. The decrease of the absorption capacity after each cycle is due to the substantial hygroscopicity of the hydrogenated products, and to oxidation of the activated surface of the samples during their removal from the reactor device for the weighing procedure.

After the second and all subsequent cycles, the melt-spun ribbons showed almost identical behavior and the same kinetic parameters, regardless of the initial state ("amorphous" or amorphous-crystalline). Moreover, the hydrogenation-dehydrogenation processes were essentially the same as in the crystalline state. Thus, the first hydrogenation cycle resulted in an irreversible transformation of the amorphous phase to a crystalline structure, as confirmed by the microstructure analysis (Fig. 7).

For practical applications of this class of materials, the dimensional factor of the hydrogenation and dehydrogenation products is essential. Experimental measurements and calculations of the average grain size in the samples were carried out by the ShaylSchwarz-Saltykov method [10]. It was found that the first cycle of hydrogenation-dehydrogenation did practically not change the grain size of the melt-spun ribbons, $d \approx 275-325 \mathrm{~nm}$ (Fig. 8a,b). The following hydrogenation-dehydrogenation cycles led to a small increase of the grain size after hydrogenation (up to $d=300-350 \mathrm{~nm}$ ) and expansion of the probable distribution region after dehydrogenation $(d=250-350 \mathrm{~nm}) \quad$ (Fig. 8c,d). Despite such small deviations in the grain size within repeated hydrogenation-dehydrogenation cycles, the hydrogen destruction method allowed achieving appropriate uniformity of the grains, which could positively affect the magnetic properties.

The investigations showed that the metal-hydride phases could easily transform during the absorptiondesorption cycles. Whereas the typical features of the hydrogenation process were the tetragonal distortion of the $f c c-\mathrm{NdH}_{2}$ hydride and the transition to the $\mathrm{Nd}_{2} \mathrm{H}_{5}$ phase, partial decomposition of the $\mathrm{Nd}_{2} \mathrm{H}_{5}$ phase and appearance of a $\mathrm{NdH}_{2}$-like structure took place under dehydrogenation. The significant difference between the elementary lattice volumes normalized to one $\mathrm{Nd}$ atom $\left(V_{\mathrm{I}}=80.75 \AA^{3}\right.$ for $\mathrm{NdH}_{2.5}$ and $V_{\mathrm{I}}=40.60 \AA^{3}$ for $\left.\mathrm{NdH}_{2}\right)$ should create static stresses that may lead to destruction of the sample. Such destruction is a typical result of cyclic transformations in intercrystalline space where hydrides are formed. The disproportionation and recombination of the $\mathrm{Nd}_{2} \mathrm{Fe}_{14} \mathrm{~B}$ main magnetic phase also play a key role in such destruction. However, the main factor is the hydrogen amount in the hydrogenated and dehydrogenated samples.

\section{Conclusions}

1. We have shown that the kinetic parameters of hydrogen absorption and desorption of $\mathrm{Fe}_{62.7} \mathrm{Nd}_{33.7} \mathrm{~B}_{1.1} \mathrm{Cu}_{1.5} \mathrm{Ti}_{1.0}$ melt-spun alloys strongly depend on the amount of amorphous phase. The higher the amount of amorphous phase, the higher the temperature and the lower the intensity of the hydrogen absorption at the first stage.

2 . By varying the parameters of the direct and reversed hydrogenation processes it is possible to achieve a structural state where two hydride phases with different crystal lattices and properties, $f c c-\mathrm{NdH}_{2}$ and $\mathrm{Nd}_{2} \mathrm{H}_{5}$, coexist.

3. Repeated hydrogenation-dehydrogenation cycling could lead to destruction of the sample due to static stresses induced by the volume changes during formation of the $\mathrm{Nd}_{2} \mathrm{H}_{5}$ and $\mathrm{NdH}_{2}$ hydrides and their accumulation. Such properties can be used to obtain microstructure with grain sizes in the range 50-300 nm.
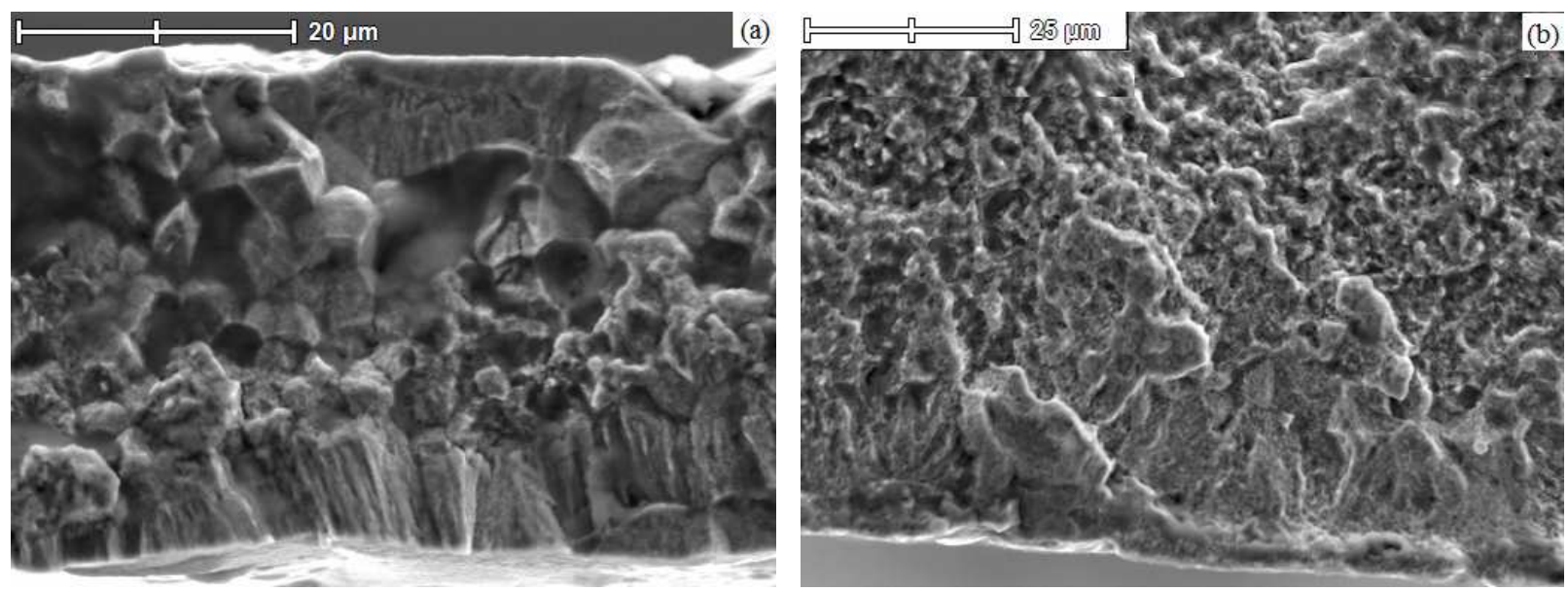

Fig. $7 \mathrm{SEM}$ images of the $\mathrm{Fe}_{62.7} \mathrm{Nd}_{33.7} \mathrm{~B}_{1.1} \mathrm{Cu}_{1.5} \mathrm{Ti}_{1.0}$ films, for the initial alloy (a) and after hydrogenation (b). 

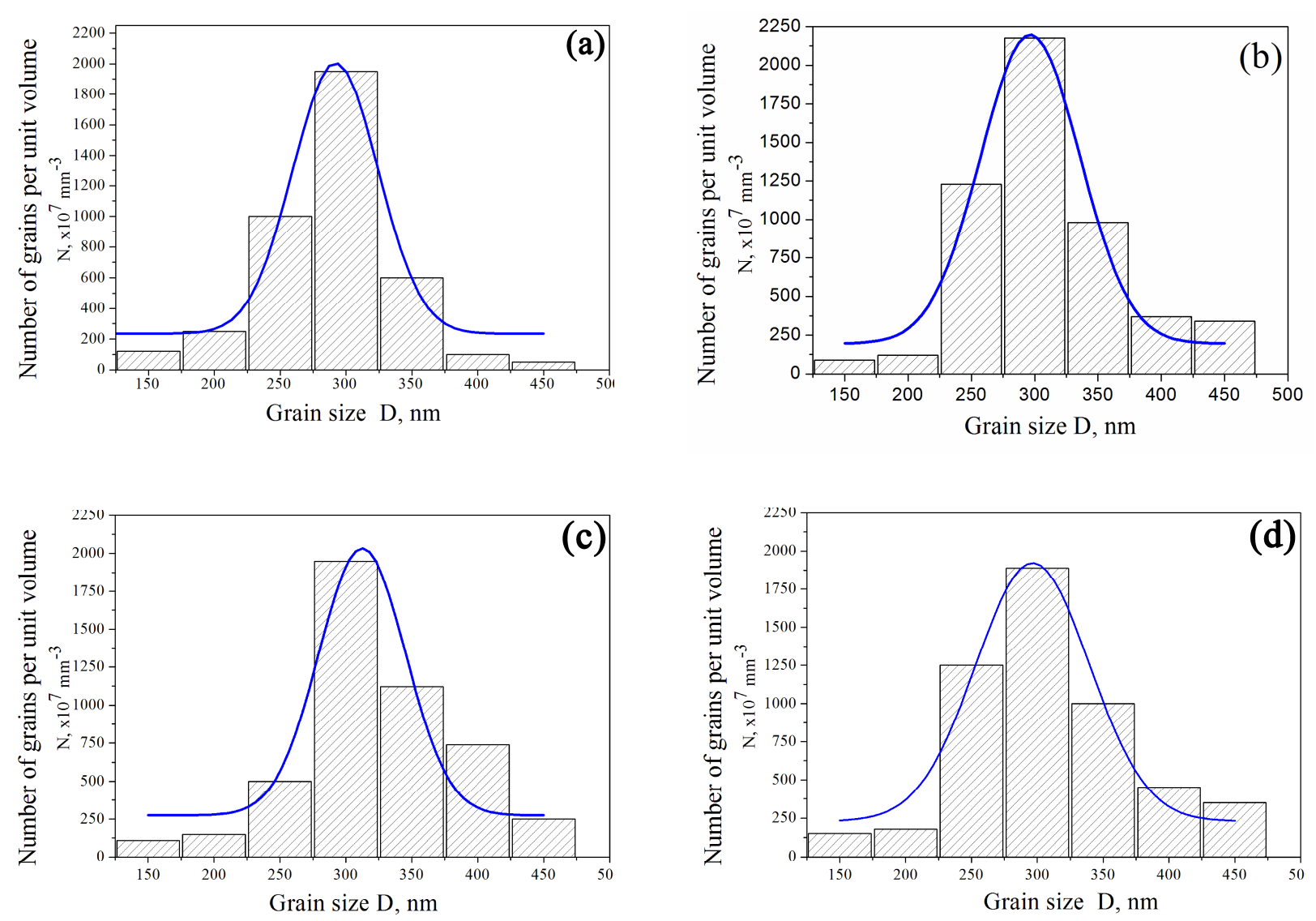

Fig. 8 Distribution of the particle size after the $1^{\text {st }}(a, b)$ and $2^{\text {nd }}(c, d)$ sorption-desorption cycle.

\section{References}

[1] G.P. Meisner, V. Panchanathan, J. Appl. Phys. 74 (1993) 3514-3518.

[2] D. Book, I.R. Harris, A. Manaf, I. Ahmad, H.A. Davies, J. Alloys Compd. 221 (1995) 180-186.

[3] J.M. Cadogan, D.H. Ryani, J.M.D. Coey, Mater. Sci. Eng. 99 (1988) 143-146.

[4] M.J. Kramer, L.H. Lewis, Y. Tang, K.W. Dennis, R.W. McCallum, Scr. Mater. 47 (2002) 557-562.

[5] Y.L. Tang, M.J. Kramer, K.W. Dennis, R.W. McCallum, L.H. Lewis, J. Magn. Magn. Mater. 267 (2003) 307-315.

[6] V. Bilovol, S. Ferrari, D. Derewnicka, F.D. Saccone, Mater. Chem. Phys. 146 (2014) 269-276.

[7] A.V. Andreev, A.V. Deryagin, N.V. Kudrevatykh., N.V. Moshnikov,
V.A. Reimer, S.V. Terent'ev, Sov. Phys. JETP 63 (1986) 608-612.

[8] S. Sugimoto, D. Book, in: Y. Liu, D.J. Sellmyer, D. Shindo (Eds.), Handbook of Advanced Magnetic Materials, Springer US, 2006, pp. 977-1007.

[9] G.F. Kobzenko, A.A. Shkola, Zavod. Lab. 56 (1990) 41-45.

[10] S.A. Saltykov, Stereometric Metallography, $3^{\text {rd }}$ Ed., Metallurgiya, Moscow, 1970, 375 p. (in Russian).

[11] P.P. Pashkov, D.V. Pokrovsky, Mining Inform. Anal. Bull. S1 (2007) 209-231. (in Russian)

[12] I.S. Miroshnichenko, Quenching from the Liquid State, Metallurgiya, Moscow, 1982, 168 p. (in Russian).

[13] G.P. Brekharya, O.A. Kharitonova, T.V. Gylyaeva, Usp. Fiz. Met. 15 (2014) 35-53. 